\title{
O Sentido da Colonização: novas abordagens
}

\author{
Luiz Guilherme S. Moreira ${ }^{1}$
}

\author{
"O capitalismo parece, pois, \\ ser no tronco da Expansão \\ Ultramarina Portuguesa um \\ enxerto - um enxerto que, como \\ freqüentemente sucede nos bacelos \\ selvagens, the permite crescer e produzir \\ fruto, sem contudo apagar totalmente \\ certos caracteres atávicos da raiz". \\ (THOMAZ: 1994, 35). \\ (...) a casualidade em história \\ não é injectiva nem sobrejectiva: \\ causas diferentes podem ter \\ os mesmos efeitos e efeitos \\ distintos resultarem da mesma causa".
} (THOMAZ: 1994, 37).

Pretende-se, através deste texto, analisar a construção de algumas retóricas que estiveram presentes ao longo da Historiografia Brasileira. Depois de apresentados alguns quadros teóricos, procuraremos demonstrar na prática, como se deu este processo. Para tal, escolhemos como foco a colonização da Cidade de São Sebastião do Rio de Janeiro, no século XVII, no período de sua efetiva política de colonização, por Portugal (apesar da cidade ter sido fundada em meados do século XVI, mais precisamente em 1565). A escolha do Rio de Janeiro nos parece ser bastante esclarecedora, já que o processo de colonização desta região se ajusta na interpretação dada por uma corrente da Historiografia Brasileira, que julgo dar melhor interpretação deste movimento.

Partindo da teoria clássica de que cada discurso histórico é fruto da influência de seu tempo, pode-se tecer alguns comentários sobre a Historiografia Brasileira.

Comecemos, pois, com um dos grandes clássicos, Caio Prado Júnior.

Em sua obra Formação do Brasil Contemporâneo, publicada em 1942. o autor monta um paradigma da colonização brasileira. Este modelo, denominado Sentido da Colonização, apontava para os objetivos do processo

\footnotetext{
${ }^{1}$ Graduação - História/UFRJ/IFCS/LIPHIS. Agradeço ao professor Dr. João Fragoso (UFRJ) por ter me iniciado na Produção Científica junto ao $\mathrm{CNPq}$, a que também sou grato pela concessão de uma Bolsa de Iniciação Científica. Assim como também agradeço a leitura atenciosa do professor Dr. Flávio Gomes (UFRJ).
} 
colonizador empreendido pela metrópole lusa. Fortemente marcada pelo marxismo e inaugurando algumas linhas mestras que serviriam de inspiração para a formulação, nos anos 60 e 70, da chamada Teoria da Dependência, esta teoria influenciaria toda a América Latina. (CARDOSO \& FALLETO, 1979)

O Sentido da Colonização deveria ser entendido como sendo a formação de uma nova sociedade, que nascia não somente em Portugal, mas em toda a Europa - principalmente Holanda, Inglaterra, França e Espanha. Sociedades estas que teriam sua base assentada em empresas comerciais. Com isto, o que viria a se tornar o Brasil, passava a ser um território altamente subordinado à metrópole. Nas palavras de Prado Júnior nota-se, então, a presença de uma História única para os diversos países europeus, pois, possuiriam a mesma estrutura.

"Aquele 'sentido' é o de uma colônia destinada a fornecer ao comércio europeu alguns gêneros tropicais ou minerais de grande importância: o açúcar, o algodão, o ouro... (...) Tudo mais que nela existe, e que é alias de pouca monta, será subordinado e destinado unicamente a amparar e tornar possível a realizaçāo daquele fim essencial". (PRADO JÚNIOR, 1969:119).

Nesta mesma linha seguiu Celso Furtado. A colônia deveria ser entendida, também, sob a presença de um alto grau de subordinação e da transferência de recursos para a metrópole. Em seu estudo sobre a economia açucareira, o autor chama a atenção para a capacidade deste sistema, de se reproduzir no período de dois anos, o que não ocorria. A reprodução não acontecia pela transferência dos capitais para a metrópole. Nesta análise podemos notar claramente a presença da Teoria da Dependência. (FURTADO, 1976).

Também pode-se notar a presença desta teoria nas obras de Fernando Novais, já no início dos anos 80. Em seu modelo, o Antigo Sistema Colonial Mercantilista existiria com a finalidade de gerar acumulação primitiva de capitais na metrópole. $\mathrm{O}$ Pacto Colonial imposto por Portugal à colônia, seria o responsável por esta acumulação, já que através deste a metrópole controlaria o preço tanto das importações como das exportações feitas pela América Portuguesa. (NOVAIS, 1983). Em resumo:

"A Caio Prado Júnior e, sobretudo, Fernando Antônio Novais, deve-se a fixação dos paradigmas referenciais que conduziram à conceituação de um determinado sistema colonial da época moderna". (...) A função precípua da colônia era, portanto, a de acelerar a acumulaşão primitiva de capitais, produzir excedentes por meio da comercialização dos produtos coloniais nos mercados europeus, lucros estes que beneficiaram diretamente a burguesia mercantil do Reino e a elite aristocrática, incrustada no aparelho de Estado" (ARRUDA, 2000:168). 
Estes autores já mostravam que não se podia entender a colônia por si só, sem uma análise da metrópole. Esta característica pode ser notada em suas análises, fortemente marcadas pela tese de António Sergio. Para este autor português, a Expansão Ultramarina de Portugal estava ligada a um movimento mais amplo: a Revolução Comercial Européia do século XI. Esta tese também recebeu grande influência do marxismo, pois se moldava perfeitamente ao determinismo histórico presente neste paradigma. Conseqüentemente, houve forte predominância de aspectos econômicos em suas análises. (SERGIO, 1980).

Para estes autores, a reprodução deste sistema de tipo escravista deve ser entendida enfocando-se a escravidão mercantil. Portanto, como a economia colonial estava subjugada ao capital comercial europeu, assim como a escravidão mercantil, como pensam os estudiosos ligados ao Sentido da Colonização, toda a lógica da montagem e da reprodução do sistema colonial, e também do modo de produção, deve ser entendida através dos fatores externos à colônia.

Enriquecendo este debate e rompendo com esta corrente ligada ao Sentido da Colonização, Ciro Cardoso, nos anos 70 , propõe a análise da sociedade colonial como sendo uma sociedade mercantil, sob o modo de produção escravista. Sociedade esta, que deveria ser compreendida pelas suas particularidades, assim como por suas relações exteriores - sendo elas complementares ou dependentes. (CARDOSO, 1973)

Rompendo ainda mais com o grupo do Sentido da Colonização, João Manuel Cardoso de Mello, chama a atenção para "(...) que modo de produção é este que não se reproduz [internamente]...?" (MELLO, 1982:42).

Aprofundando ainda mais este caráter particular, Fragoso \& Florentino apontam para um tipo de reprodução único, em que o capitalismo mercantil não possui muita importância, ou seja, não é a chave principal para o entendimento da reprodução do sistema. O econômico, portanto, não é o aspecto mais importante (FRAGOSO \& FLORENTINO, 1993). Assim como os estudiosos ligados ao Sentido da Colonização, esses dois autores chamam a atenção para a compreensão da História do Império Português, e seu caráter particular principalmente, no que diz respeito ao não enquadramento de Portugal num sistema feudal clássico, e consequentemente sua superação. Para isso se torna necessário entender à qual interpretação da Expansão Ultramarina e da própria formação do Reino de Portugal, estes historiadores se vinculam.

Se por um lado, os historiadores do Sentido da Colonização vinculamse ao modelo de sociedade portuguesa proposto por Antonio Sergio, este novo grupo, particularmente Fragoso \& Florentino, entende a sociedade portuguesa do período similarmente a Thomaz, que em linhas gerais diz: 
"(...) a burguesia em Portugal não se apropriou do Estado. nem impôs os seus valores. nem mesmo criou uma consciência autônoma de classe, é por demais evidente". (THOMAZ, 1984:13).

O pequeno detalhe, porém de grande importância, que leva à compreensão da sociedade portuguesa, é saber relacionar a Expansão Ultramarina Portuguesa com a Revolução Comercial do século XI. Este foi o grande erro dos estudiosos ligados ao Sentido da Colonização. Como nos chama a demonstra mais uma vez Thomaz.

\begin{abstract}
"O nexo entre a expansão portuguesa e o desenvolvimento das redes marítimas da Revolução Comercial do século XI decorrente, é pois inegável. Resta, porém, aparecer a sua natureza - se de causa a efeito ou de teorema a corolário (...) com efeito, estar a chave do problema da gênese da expansão portuguesa e das suas relações com a expansão européia" (THOMAZ, 1984:15).

"As relações entre a Expansão Portuguesa e a Expansão Européia em geral parecem assim extremamente complexas e subtis - nem meramente externas e acidentais, nem intrinsecas e necessárias, mas, por assim dizer dialogais". (THOMAZ, 1984:36).
\end{abstract}

Mas vamos ver, mais detalhadamente, como foi a construção do Estado de Portugal, assim como a importância da Expansão Ultramarina para este e para os demais grupos que compunham este Estado.

Portugal, assim como a Espanha, vinha desde o século XI reconquistando suas terras, nas mãos dos mouros. Nesse processo de reconquista começava a haver uma centralização do poder, assim como uma incorporação de novas terras e homens. A centralização do poder não se deu através de guerras entre casas aristocráticas do Norte, e sim através de um fortalecimento de um dos Senhores.

Durante a Revolução de Avis (1383-1385), Portugal começa a delinear sua saída para a crise do século XIV. Esta Revolução foi um choque de conflitos entre parte da alta nobreza (que buscava através da união com Castela, a obtenção de novas terras para retornar as suas rendas ao patamar anterior à crise) e o restante da alta nobreza e pequenos nobres, burgueses e artesãos (que temiam perder sua influência se Portugal fosse anexada à Castela). Deste choque, o grupo do restante da alta nobreza - os pequenos nobres, burgueses e artesãos - saiu vitorioso.

No período anterior à Revolução de Avis, portanto no tempo da reconquista, o processo de centralização do reino se deu através da expansão do Condado Portucalense do norte, para o sul. Com a expansão das terras do que viria a pertencer ao Rei de Portugal, a pequena nobreza e os fidalgos que não eram nobres de primeira classe, passam através do Sistema de Mercês, a possuir uma certa autonomia frente aos senhores do norte. Passa a haver, nessas áreas, um sistema fiscal unificado e uma "burocracia". Por isso, a pequena nobreza não se juntará aos grandes senhores do norte na Revolução de Avis. 
Já o apoio dos burgueses e dos artesãos se deve à presença dessas classes, no universo mercantil das cidades portuárias - Porto, Vianna e Lisboa que com a "Revolução Comercial", se tornaram intermediários entre o sul e o norte da Europa. Estas cidades eram administradas por uma oligarquia de mercadores urbanos localizados nos concelhos, onde se organizava a distribuição de terras e o abastecimento. Este grupo tinha sua renda baseada no controle do abastecimento, o que lhe permitia determinar os preços de certos produtos; utilizando o público, para o enriquecimento privado. O Estado se fazia presente através da Justiça e do Fisco - parte deste imposto ia para o Estado. Também devido a este quadro, os burgueses e artesãos não podiam compartilhar da mesma solução apontada pelos grandes senhores do norte.

Diante deste quadro de conflito, a Expansão Ultramarina não foi somente uma resposta à crise do século XIV; foi, também, uma grande solução de compromisso entre os diversos grupos - parte da nobreza, comerciantes e Estado.

A nobreza se encontrava sufocada, devido a crise do Século XIV, suas rendas haviam diminuído e sua classe encontrava-se hipertrofiada - devido ao ingresso da pequena burguesia, dos fidalgos e de comerciantes que compravam títulos de nobres - e em choque com a crescente centralização do Estado. Para as nobres a Expansão significava o aumento das rendas, para alguns através de Cargos públicos e para outros, num primeiro instante, por meio de pilhagens e do saque das terras conquistadas, e num segundo momento a obtenção de terras. Posteriormente, esta aristocracia se transformaria na figura do fidalgoneercador, que utilizaria os lucros do comércio ultramarino para a manutenção do status quo.

Para os comerciantes, abre-se a oportunidade de controlar as novas rotas comerciais. Depois que o Rei começa a beneficiar mais a aristocracia, na concessão de rotas, eles começam a ingressar nos quadros aristocráticos por rmeio de compras de títulos, ou de união matrimonial. Acabam assim por se tornar mercadores-fidalgos, influenciados também pelo caráter aristocrático de siua sociedade. (GODINHO, 75:71-116).

O Estado aumenta seu sistema físcal; passa a não depender do campesinato - reduzindo o conflito com a aristocracia; e consegue duas principais vantagens: se firma contra Castela e consegue garantir a paz interna.

Voltemos, então, ao quadro teórico proposto for Fragoso \& Florentino. Ao questionarem os modelos do grupo ligado ao Sentido da Colonização, quanto à maneira de reprodução do sistema, percebem que os paradigmas nıontados não conseguem dar conta disso, uma vez que a acumulação feita no i tterior daquele sistema era insuficiente para tal. O sentido da colonização cleveria, então, ser outro, que não só o econômico. 
Assim como o grupo do Sentido da Colonização, eles propõem que a sociedade colonial era idêntica à sociedade portuguesa. No entanto, diferem quanto às características desta sociedade. Enquanto para os clássicos a sociedade portuguesa passa por uma transformação da sociedade do Antigo Regime para uma sociedade capitalista; para Fragoso \& Florentino, ela ainda permanece no Antigo Regime, com fortes características estamentais, com já vimos. Portanto, a sociedade portuguesa e consequentemente a colonial, permanecem com características excludentes e preocupadas com a manutenção da ordem. A reprodução passava pelo comércio, o que poderia acabar por gerar uma burguesia mercantil autônoma. No entanto, o próprio comércio, por meio do Pacto Colonial, era auto-regulamentado pelas companhias monopolistas e pela concorrência entre comerciantes portugueses. Mesmo assim, ainda era possível criar fortes comunidades mercantis na colônia.

A estrutura da produção tinha por base a incorporação de fatores abundantes na colônia e de baixo custo: terras, alimentos e mão-de-obra. Consequentemente, podia apresentar certa autonomia frente ao mercado internacional. Logo, se a estrutura tem uma relativa autonomia, sua reprodução não passa somente por fatores externos, qual seja, pelo comércio com a metrópole. Percebe-se ali a mesma característica excludente da metrópole, na colônia. Para demonstrar isso trabalhemos, então, com o exemplo da colonização do Rio de Janeiro. Como existiram duas etapas de colonização, há que se escolher uma.

Descarta-se um primeiro momento, entre 1565 - c.1650, em que a importância da cidade esta mais ligada a questões estratégicas do que propriamente à lógica colonizadora portuguesa.

\begin{abstract}
"Las informaciones disponibles acerca de Río de Janeiro en las últimas décadas del siglo XVI, no muy numerosas, permitem constatar, de todos modos, tratarse entonces de um pequeñisimo núcleo creado como centro de actividades militares (en esa época, sobre todo en contra de los franceses), de exploración y conociminento del interior, de control de los indios; y cada vez más, de faenas de pescas y agropecuarias." (CARDOSO \& ARAUJO, 1992:53).
\end{abstract}

Somente a partir de meados do Século XVII, a cidade vai se transformando e adquirindo características particulares, por diversos fatores. Exemplifiquemos alguns.

A Virada portuguesa para o Atlântico, no século XVI, mas especialmente depois do de 1628-1633, colocou a colônia portuguesa na América como fonte principal de riqueza da metrópole, através de taxações sobre o comércio. Gradativamente, o maior centro produtor de açúcar do sul se desloca de São Vicente para o Rio de Janeiro. O porto do Rio começa a ganhar grande importância, não só pelas exportações de açúcar, mas também devido ao comércio com outras regiões da colônia. 
Em 1642, quando já havia sido restaurada a monarquia, os chamados homens bons passam a ter os mesmos privilégios de que gozavam seus semelhantes no Porto. Comerciantes e donos de barcos são autorizados a realizarem comércio direto com a África, em 1640. Há a criação do bispado local, em 1676. E principalmente, nas palavras de Cardoso \& Araújo, já se vislumbrava uma grande estratificação social.

"Pero todavía en el siglo XVII, esos y otros mestizos fueron ya hallando limitaciones y dificuldades cada vez mayores: uma estratificación sociétnica se formaba y, sobre todo en el siglo XVIII, tendió a volverse legal". (CARDOSO \& ARAUJO, 1992:84).

"En 1695, el viajero francés Froger constató en Río la coexistencia de gente muy rica. con gente extremamente miserable. Mencionó más especialmente a los habitantes ricos, posedores de multitud de esclavos y algumas familias de indios en sus ingenios. Los grandes propietarios rurales - como los comerciantes más importantes y los eclesiásticos de alta jerarquía - vivian. en el lujo y, según el francés, en considerable depravación. La crítica popular al respecto se concentraba en los hombres de la Igreja. Otras fuentes de esa época hablan del gran consumo que hacían los ricos de Río de Janeiro de productos europeos: vino, queso, aceite, artículos de-metal, terciopelos, sedas, tafetanes..." (CARDOSO \& ARAUJO, 1992:85).

Este elevado grau de estratificação social, acabou por gerar dificuldades para as classes mais baixas da população. Mais uma vez citamos Cardoso \& Araújo. Embora possa parecer um pouco extensa, a citação é bastante esclarecedora, uma vez que nos dá um panorama de como tamanha diferenciação afetava a qualidade de vida da população.

"En la medida en que la estratificación mencionada separa una pequeña minoría de privilegiados - habia sólo 150 portugueses entonces - de la inmensa mayoría no privilegiada (en aquella época, los esclavos indios, muy mumerosos, aunque su número no sea conocido; los esclavos africanos en cantidad cresciente, asimismo, los indios y mestizos libres), se trataba de algo que empezó a tener consecuencias importantes desde el siglo XVII, cuando empezaron las crisis en el suministro de alimentos a las ciudades del litoral de Brasil. Tales crisis afectaron preferentemente a las personas menos privilegiadas, que no tenían los recursos que les permitieram el consumo de lo que venía de Europa, ni tampoco poseiam tierras y esclavos - para no mencionar a los esclavos mismos, desde luego -. Aunque la pequeñez de la ciudad en el siglo XVI hacía fácil la solución de la cuestión de cómo alimentar a sus habitantes, no caben muchas dudas de que el tipo de sociedad- que desde entonces se estaba constituyendo, con sus contrastes sociales tan marcados, ya preparaba alguns de los problemas urbanos de los demás siglos coloniales." (CARDOSO \& ARAUJO, 1992:53-55).

Parece-me, então, que o exemplo do Rio de Janeiro pode ser adotado, visto que temos aí um local privilegiado, para compreender este projeto colonizador. Porém, foi demonstrada somente a presença marcante das diferenças sociais, faltando, pois, demonstrar como se dava a construção desse mecanismo. Para isso, mais uma vez podemos tomar o exemplo do Rio, respeitando o mesmo corte temporal, qual seja, meados do século XVII.

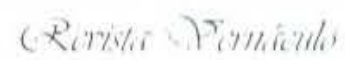


Para compreendermos a diferenciação e o processo de exclusão, tornase necessário entender o processo formador das unidades produtivas. Descartada a atividade manufatureira, proibida pela metrópole, resta-nos apenas atividades ligadas à agricultura. Para a implementação e a reprodução desta atividade, à grosso modo, são necessários três pilares fundamentais: mãode-obra, terras e capitais (FRAGOSO, 1995). Dado que a sociedade colonial não possuía liquidez monetária suficiente, consequentemente havia uma baixa acumulação e a reprodução deveria ser feita por meio de cadeias de endividamento, portanto, caracterizando uma economia do tipo pré-capitalista. Este tipo de sistema já mostra por si só um quadro de exclusão, na medida em que somente pessoas no topo da hierarquia econômica e social poderiam ingressar na cadeia de endividamento, tendo assim acesso à aquisição de escravos e terras. Consequentemente, quem está fora do topo não tem possibilidade de entrar no sistema, vivendo à margem da sociedade. No entanto, não se deve pensar que os três pilares fundamentais eram adquiridos somente com o processo de endividamento.

O grosso da obtenção de terras não passava pela compra, e sim pelo sistema de sesmarias. A sesmaria no Brasil-colônia possuía aspectos diferentes das concedidas em Portugal. Enquanto em Portugal elas deveriam manter a estrutura da sociedade, baseada na subordinação do camponês ao aristocrata; no Brasil possuíam um caráter excludente. (FRAGOSO, 1997:15)

Fragoso, ao estudar a elite carioca em meados do XVII, demonstra que as sesmarias foram recebidas em maior número pelo grupo de famílias que possuíam laços sociais entre si, grupo este que ele denominou de GPS (Grupo de Parentesco Senhorial); enquanto que o grupo FSA (Famílias Sem Aliança) recebeu menos este tipo de Mercê. Portanto, dentro da própria elite havia uma estratificação. O grupo FSA deveria buscar mais o mercado para se reproduzir. A população pertencente aos grupos mais baixos da hierarquia também deveria buscar a obtenção de terras no mercado, visto que estavam afastados da concessão de sesmarias. $\mathrm{O}$ autor demonstra que $70 \%$ das compras de terras eram feitas por donos de engenhos pertencentes à elite, o que caracterizava a exclusão das camadas populares do mercado de terras.

Passemos para a obtenção da mão-de-obra. Embora, em finais do século XVII, a mão-de-obra africana já se constituísse em uma parte importante dos cativos, a escravidão indígena ainda estava fortemente presente. Apesar da tentativa de proteção dos indígenas feita pela Coroa e pelos padres jesuítas, os índios continuaram sendo escravizados pelos colonos. Estes colonos, os chamados homens bons, pertenciam aos quadros administrativos da colônia, e se aproveitavam de sua posição para transformar os índios em cativos. Vale lembrar, também, que muitos destes administradores vieram de Portugal, com a missão de proteger a colônia de ataques, não só franceses e holandeses, mas 
também indígenas. Assim, possuíam acesso direto à mão-de-obra nativa. $\mathrm{O}$ que é de fundamental importância, pois nos primeiros engenhos se utilizava mãode-obra indígena. Estes administradores, que nada mais eram do que militares, também recebiam terras como Mercê.

O crédito também constituía um fator de exclusão social, em uma economia, como já foi dito, em que havia uma precária liquidez de capitais. Este crédito era concedido através de cadeias de endividamento. O maior credor o Juizado de Órfãos, um órgão público, financiava a reprodução da economia colonial. Os Juizes de Órfãos, também uma Mercê, pertenciam ao grupo dos GPS, e decidiam para quem o crédito deveria ir; não raro o cargo passava de pai para filho. O grupo dos GPS foi responsável pela obtenção de $45,2 \%$ dos créditos, enquanto o FSA ficou com $24,7 \%$.

Vimos, então, que tudo passava por um ciclo restrito de pessoas, pertencentes ao topo da hierarquia, o que acabava por limitar a mobilidade social, algo típico do Antigo Regime. A montagem e a reprodução do sistema não passava somente por questões econômicas; a política possuía uma grande importância. Nas palavras de Fragoso:

\footnotetext{
"O que acabei de afirmar adquire mais sentido quando lembramos que estudamos uma economia que, nos seus primeiros tempos, era marcada por uma baixa taxa de acumulação c por uma precária liquidez, mas que também se caracterizava por uma 'disponibilidade' de terras e índios (leia-se mão-de-obra). A isto se agrega, ainda, o fato de que a colonizaçāo seria feita por homens saídos de uma sociedade de tipo Antigo, ela própria ceifada por privilégios e pela exclusão social, onde produção de riqueza é vista como sinônimo de apropriação do trabalho alheio. (...) E da mesma maneira, não é de se estranhar que, uma vez feita aquela captura de fatores a sua distribuição fosse um fenômeno da política." (FRAGOSO, 1995:59-60) ).
}

Este tipo de sociedade, só será superado quando a utilização do trabalho compulsório africano superar o indígena e gerar assim uma escravidão mercantil intensa. Este tipo de sistema levaria a imobilização de capital, durante um certo tempo, por parte do senhor. Capital este, que vai para as mãos de um comerciante, o quc poderia levar a um grau de endividamento, por parte do senhor, insuportável. O que acarretaria a falência dos grupos senhoriais e ao surgimento de uma grande classe mercantil, que acabaria com esse processo de exclusão, ampliando as possibilidades deste grupo conseguir subir na hierarquia social. Esgotando-se, assim, todo o sistema, se, por ventura, não houvesse outro traço arcaico marcante na sociedade.

Embora tal característica comesse a aparecer somente no início do XVIII, merece uma rápida abordagem. O arcaico aparece quando os comerciantes conseguem acumular grandes capitais, em detrimento dos senhores. Esta acumulação acabaria por esterilizar o sistema. Todavia, o mesmo não ocorre por alguns fatores, dos quais podemos citar, o reinvestimento deste 
capital em setores agrícolas, que embora menos lucrativos, em termos sociais, dava mais destaque aos seus investidores. Assim, essa parcela de comerciantes, reintroduzia o capital no circuito, seja através da aquisição de fazendas, seja através de casamentos com famílias ligadas ao setor agrícola. O que nos remete novamente, ao fato de não podermos analisar a sociedade colonial, somente pelos seus fatores econômicos, o social neste caso é muito mais importante.

Se tentarmos ampliar a visão para outra área da colônia, por exemplo o Recôncavo Baiano, a principal região da colônia no período, vamos notar algumas semelhanças e diferenças, que, no entanto, não mudam o panorama excludente da sociedade aqui montado. Procurarei ser breve.

Schwartz, ao estudar o Brasil-colônia, mais especificamente a Bahia, também nota uma diferenciação social. Aponta para uma sociedade altamente hierarquizada, de acordo com a raça à qual pertencia o indivíduo, condição sine qua non para o seu grau de pertencimento aos estratos sociais. (SCHWARTZ, s/d: 199) No que diz respeito ao início do sistema e sua reprodução, Schwartz também aponta para altos gastos, com a presença de créditos. O capital necessário para tal, durante o século XVI, teria vindo diretamente da Europa. Posteriormente, já no século XVII, parece não haver tal investimento. Neste período a acumulação para montagem do sistema, poderia vir de dois modos. Primeiro, o agricultor se dedicava ao produzir gêneros para abastecimento interno, principalmente alimentos, e depois montava seu próprio engenho. Segundo, plantava cana-de-açúcar em seu terreno e moía em um engenho de terceiro e posteriormente montava o seu próprio. Os empréstimos também poderiam ser feitos por comerciantes e profissionais urbanos. Quanto aos créditos, também poderiam vir de instituições religiosas, como Ordens Terceiras, entre outras, das quais fazia parte a elite colonial. Os créditos daí conseguidos iam majoritariamente para a instalação de novos engenhos, sendo os empréstimos para financiar a produção. (SCHWARTZ, s/d:203 e 214-15).

Os primeiros proprietários de engenhos também eram oriundos de grupos de conquistadores, que enxergaram no açúcar uma maneira de adquirir algum status, uma vez que se admitia que o título de proprietário de engenho era equivalente ao de conde em Portugal.

"El luchar para obtener una posición social y su reconocimiento a través de los símbolos de nobleza tradicionales - títulos, órdenes militares y vínculos de propriedad deben ser vistos como um signo predominante de la clase plantadora" (SCHWARTZ, $\mathrm{s} / \mathrm{d}: 210)$.

Para concluir se, por ventura, pode-se falar em um único projeto para a colonização brasileira, este, ao meu ver, não pode ser entendido como um projeto somente mercantil, com sua política mercantilista. Deve-se entender as nuanças políticas existentes nestes projetos, como foi o caso do Rio de Janeiro. 
Qual seria este projeto? Em linhas gerais, a construção de uma sociedade baseada num alto grau de diferenciação social, diferença esta, que começava no político-social e findava no econômico. O que caracterizava uma sociedade tipicamente do Antigo Regime, portanto ainda ligada mais à Época Medieval, do que à Época Moderna - leia-se capitalismo - diferentemente de como pensavam nossos clássicos da Historiografia Brasileira.

Mais ainda, o capitalismo no Norte da Europa, principalmente na Inglaterra e na Holanda, começava a florescer, isto não quer dizer que as demais sociedades que se relacionavam com estas tivessem que adotar tal sistema. Foi justamente isto o que ocorreu. O capitalismo na Sociedade Portuguesa serviu para mantê-la viva, sem, contudo fazer com que a sociedade sofresse grandes mutações, podendo assim manter certos caracteres atávicos da raiz. Portanto, os mesmos efeitos - as expansões nacionais, podem ter causas diferentes, pois as sociedades - portuguesas, inglesa e Holandesa - são diferentes.

Junho, 2000.

A Danielle, que nos descaminhos da História me mostrou o caminho do amor. 


\section{Bibliografia}

- CARDoso, Ciro. Sobre los Modos de Producción Coloniales de América. In ASSADOURIAN, Carlos Sempat et al. Modos de producción en América Latina. Cordoba, Cuadernos de Pasado y Presente n 40, 1973.

- $\quad$---- \& ARAUJO, Paulo H. Rio de Janeiro. Madri: Mapfre, 1992.

- CARDoso, Fernando Henrique e FAlleto, Enzo. Dependência e Desenvolvimento na América Latina. Rio de Janeiro: Zahar Editores, 1979, $5^{\text {a Edição. }}$

- FRAGOSO, João. À espera das frotas: hierarquia social e formas de acumulação no Rio de Janeiro, século XVII. Rio de Janeiro: LIPHISUFRJ, 1995, pp. 53-62.

- ----. Introdução. In Documentos Históricos - Vol. CXI.- tombos das cartas de sesmarias do Rio de Janeiro dadas por Cristóvão de Barros (157374) e Salvador Correia de Sá (1578-79). Rio de Janeiro: Ministério da Cultura, Fundação Biblioteca Nacional, Departamento Nacional do Livro, 1997.

- - ----. A nobreza da República: notas sobre a formação da primeira elite senhorial do Rio de Janeiro (séculos XVI e XVII). Rio de Janeiro: Mimeo inédito, 2000.

- - \& Florentino, Manolo. O Arcaísmo Como Projeto. Rio de Janeiro: Diadorim, 1993.

- FURTADO, Celso. Formação Econômica do Brasil. São Paulo: Companhia Editora Nacional, 1976.

- GODINHO, Vitorino. Estrutura da Antiga Sociedade Portuguesa. Lisboa: Arcádia. 1975, $2^{a}$ Edição, s/d.

- MELlo, João Manoel Cardoso de. O Capitalismo Tardio. São Paulo: Brasiliense, 1982.

- NOVAIS, Fernando. Portugal e Brasil na Crise do Antigo Sistema Colonial (1777-1808). São Paulo: Hucitec, 1983.

- PRADO JÚNIOR, Caio. Formação do Brasil Contemporâneo. São Paulo: Editora Brasiliense, $9^{a}$ Edição, 1969.

- SERGIO, Antonio. A Conquista de Ceuta. In Ensaios. Lisboa: Sá da Costa,

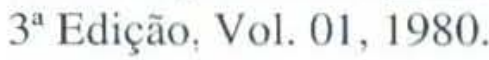

- SCHWARTZ, Stuart. Brasil Colonial: Plantaciones y Periferias, 1580,1750. In BETHELL, Leslie (org.). Historia de América Latina - vol. 03.Barcelona: Editorial Critica, s/d, pp. 191-259.

- TENGARRINHA, José. História de Portugal. São Paulo: Editora Unesp e Edusc, 2000.

- ThOMAZ, Luís. De Ceuta a Timor. Lisboa: DIFEL, 1994. 